\title{
Unilateral Pseudotumoral Presentation of Cerebral Venous Thrombosis
}

\section{Apresentação Pseudotumoral Unilateral da Trombose Venosa Cerebral}

\author{
Leonardo Halley Carvalho Pimentel ${ }^{1,2}$, Francisco José Mont’Alverne ${ }^{3}$, Francisco de Assis Aquino Gondim ${ }^{3}$
}

1. Faculdade de Ciências Médicas, Universidade Estadual do Piauí, Teresina, Piauí, Brazil. 2. Disciplina de Neurologia, Faculdade Integral Diferencial, Teresina, Piauí, Brazil. 3. Hospital Universitário Walter Cantídio, Universidade Federal do Ceará, Fortaleza, Ceará, Brazil.

\begin{abstract}
Cerebral venous thrombosis (CVT) is an unusual cause of stroke. It is more common in middle-aged women. Deep CVT lesions are usually bilateral. CVT can have very diverse clinical presentations and mimic other conditions. We report two women with CVT initially diagnosed as tumors (unilateral pseudotumoral presentation of CVT) successfully treated with intravenous heparin. Early diagnosis was important and completely reversed the symptoms. The diagnosis of CVT should be remembered when the clinical picture is compatible even if brain imaging suggests unilateral tumor.
\end{abstract}

Key words: Cerebral venous thrombosis. Pseudotumoral presentation. Neuroimaging.

\section{Resumo}

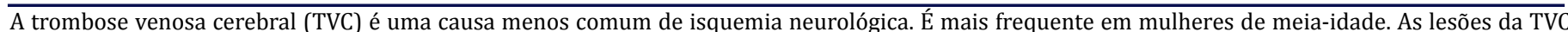
profunda são geralmente bilaterais. TVC pode ter muitas apresentações clínicas e simular outras patologias. Nós relatamos os casos de duas mulheres com TVC inicialmente diagnosticadas como tumores (apresentação pseudotumoral unilateral da TVC) com boa evolução clínica após tratamento com heparina intravenosa. 0 diagnóstico precoce foi importante para a reversão completa dos sintomas. 0 diagnóstico de TVC deve ser lembrado sempre que o quadro clínico for compatível mesmo que a neuroimagem sugira tumor unilateral.

Palavras-chave: Trombose venosa cerebral. Apresentação pseudotumoral. Neuroimagem.

\section{INTRODUCTION}

Cerebral venous thrombosis (CVT) can present with a wide variety of findings in clinical history and physical examination, which often delay correct diagnosis ${ }^{1}$.

We present two cases in which the brain images initially led to the diagnosis of unilateral brain tumors but turned out to be CVT after further evaluation and successful treatment.

\section{CASE REPORTS}

\section{Case 1}

A 27-year-old woman was admitted to an emergency room with sudden drowsiness, confusion and right hemiplegia and hemisensory loss. In the previous week she had complained of headache and vomiting. An initial head computed tomography (CT) revealed a well circumscribed hypoatenuated lesion in the left thalamus without edema (Figure $1 \mathrm{~A}$ ) and a subsequent brain magnetic ressonance (MR) imaging confirmed the presence of the left thalamic well-circumscribed hyper intensity on fluid attenuated inversion recovery (FLAIR) MR images without enhancement after gadolinium (Figure $1 B$ and $1 C)$, which was considered to be a low grade glioma. She had a history of chronic smoking, use of parenteral contraceptives for two years and had preeclampsia seven years before the admission. Three days after admission, her clinical condition deteriorated and she became stuporous. A cerebral angiography disclosed extensive central venous thrombosis affecting the superior sagittal sinus, left transverse sinus, the inferior sagital and the straight sinus as well deep cerebral veins (not shown) She was transferred to an Intensive Care Unit and i.v. heparin was started and the patient experienced marked clinical improvement in the following days. Repeated Head CTs revealed slight hemorrhagic transformation and subsequent complete regression of the left thalamic hypodensity (Figure 1D). The patient was discharged home on warfarin, without any motor or cognitive impairment. Over the following year, she had minor headaches and warfarin was discontinued after one year without any recurrence of the symptoms. Laboratory investigations revealed positive antinuclear antibodies (1:32) but other known causes of thrombophilia were excluded.

\section{Case 2}

A 66-year-old woman was brought to the Emergency Room with headache, mild left hemiparesis and bilateral papilledema. A Head CT without contrast revealed intracerebral hemorrhage in the right frontal and parietal lobes with surrounding edema

Correspondência: Leonardo Halley Carvalho Pimentel, Av Higino Cunha, 1515, Teresina, Piauí, Brasil, 64.014-220. fax: 55-86-3198-1500. E-mail: pimentelhc@hotmail.com

Conflito de interesse: Os autores declaram não ter conflito de interesses

Recebido em: 20 Jun 2014; Revisado em: 01 Jul 2014; Aceito em: 04 Jul 2014 
suggestive of a metastatic tumor (Figures 2A and 2B). A Brain $M R$ imaging revealed increased vascular enhancement around the hemorrhage and the surrounding edema, suggesting the presence of an arteriovenous malformation (Figure 2C). A cerebral angiography revealed superior sagittal and right transverse sinuses thrombosis (Figure 2D).

Figure 1. (A) Head CT revealed hypodensity in the left thalamus. (B) Axial FLAIR MRI shows well-circumscribed area of increased signal intensity in the left thalamus (C) without enhancement after gadolinium i.v. injection in axial T1 weighted MRI. (D) The last Head Computerized Tomography after three months from admission shows recovery of prior.

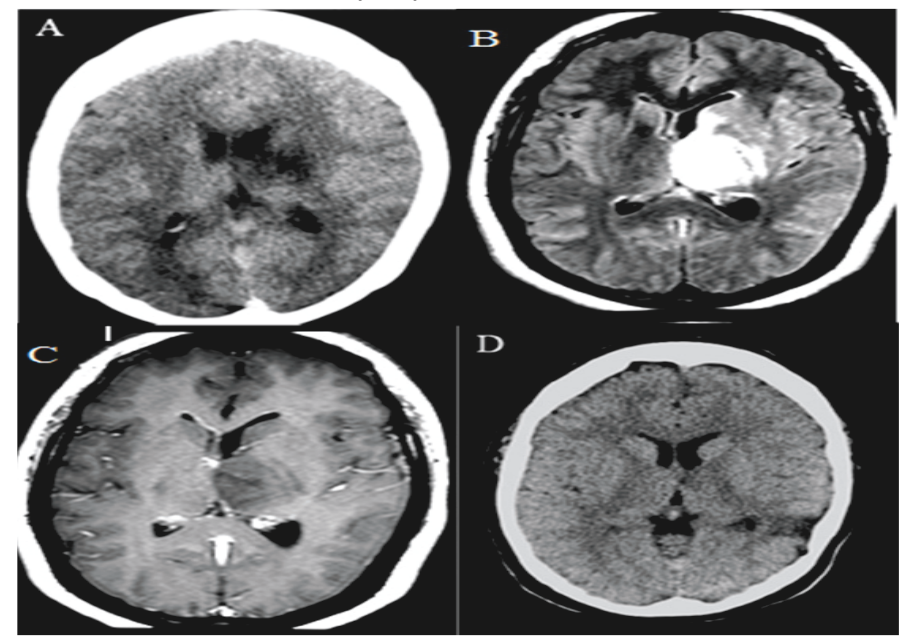

Figure 2. (A) and (B) Head CT shows parietal hemorrhagic lesion with surrounding edema. (C) Fluid-attenuated inversion recovery (FLAIR) MR image demonstrates a hypointense frontoparietal lesion with marked edema surroding the hemorrage. Note multiple lesions in the frontal white matter most of the lesions are hyperintense, but some are hypointense, representing dilatation of the parenchymatous veins due to collateral circulation (black arrows). (D) Cerebral angiography demonstrates partial filling in the periphery (black arrow) with filling defect in the central portion (arrow head) of the superior sagital sinus. There is lack of flow in the right lateral sinus (white arrows) with collateral circulation through parenchymatous dilated veins (white head arrows), findings consistent with thrombosis.

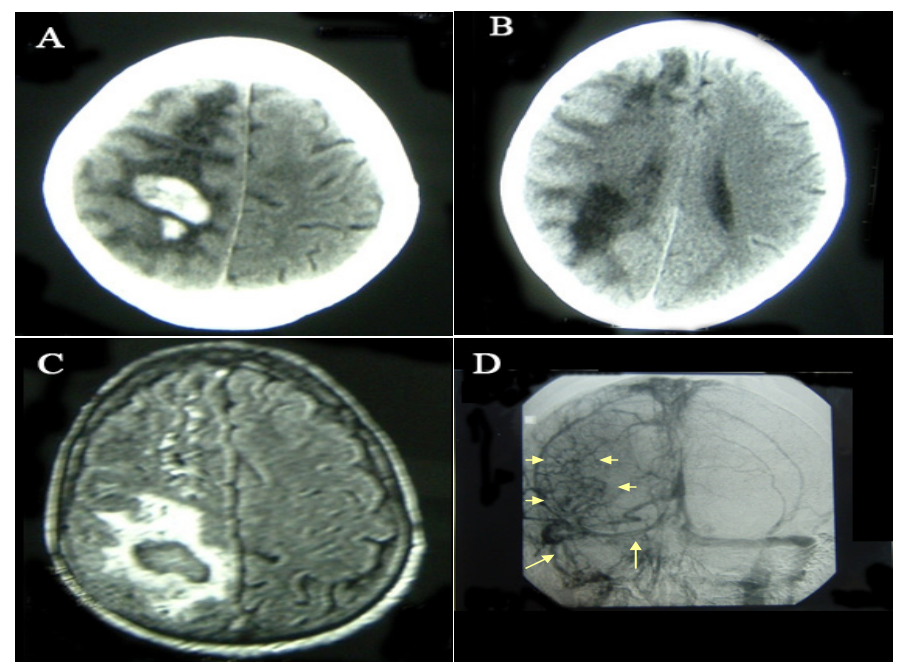

Intravenous heparin was started. Left hemiparesis and the headache subsequently improved. She was discharged home on warfarin. Laboratory investigations for thrombophilias including blood levels of proteins $\mathrm{C}$ and $\mathrm{S}$, antithrombin III, lupus anticoagulant and anticardiolopin antibodies, homocysteine, Leiden mutation, methylene tetrahydrofolate reductase mutation, thyroid hormones, antinuclear antibody were all negative. One year after the initial event, warfarin was discontinued without recurrence of the symptoms, repeated cerebral angiography and Head CT did not disclose residual CVT.

\section{DISCUSSION}

Cerebral venous thrombosis is an uncommon, but alarming disease. Two different phenomena underlying CVT should be distinguished: thrombosis of the cerebral veins, with local effects caused by venous obstruction, and thrombosis of the major sinuses, which causes intracranial hypertension. In the majority of cases, these two processes occur at the same time ${ }^{2}$.

Initial presentation includes headache of variable severity with increased intracranial pressure, and cerebral venous infarcts which are often associated with hemorrhagic transformation. These findings can result in neurological deficits, seizures, decreased consciousness and even death ${ }^{3}$.

The mode of onset is very uncertain, from sudden to progressive over weeks, and can be confused with a large variety of conditions including tumor ${ }^{3}$, as seen in our cases.

Brain imaging by itself is frequently nonspecific (infarct, hemorrhage or edema) and can be normal in up to $25 \%$ of patients (specially non-contrast Head CT), reinforcing the need for clinical correlation. Imaging of the venous system is essential to diagnosis and may show either the intravascular thrombus or the occluded vessel. Head CT is still considered to be the standard brain imagin for investigation on emergency services but the best diagnostic tool is the combination of T1-weighted spin echo and T2SE MRI sequences and magnetic resonance venography to show intravascular thrombus and to detect the nonvisualization of the same vessel, respectively ${ }^{4,5}$.

Many conditions are associated to CVT like antithrombin deficiency, protein $\mathrm{C}$ and $\mathrm{S}$ deficiencies, antiphospholipid antibodies, malignancies, dehydratation, surgical procedures, systemic and inflammatory bowel diseases, infectious diseases, among others ${ }^{3}$. In women its association with pregnancy and puerperium and with the use of oral contraceptives is wellestablished $^{6}$.

Pseudotumoral presentation of CVT has been occasionally described, but unilateral pseudotumoral presentation is particularly uncommon and can delay correct diagnosis. A pseudotumoral cerebellar infarct with unilateral cerebellar lesion with contrast enhancement was only diagnosed after surgical operation?.

In most of cases of CVT, oral anticoagulation is given for 
3-12 months ${ }^{8}$. Decisions to initiate, continue or withhold anticoagulation therapy in patients with CVT depend on the risk of recurrent thrombosis and relative morbidity and mortality and risk of hemorrhagic complications ${ }^{9}$. In summary, the early and correct recognition of CVT is essential to define appropriate therapy and improve prognosis. Pseudotumoral presentations of CVT even when unilateral should be in the differential diagnosis of emergency room physicians especially in high-risk groups.

\section{REFERENCES}

1.Kuehnen J, Schwartz A, Neff W, Hennerici M. Cranial nerve syndrome in thrombosis of the transverse/sigmoid sinuse. Brain 1998;121:381-8

2.Stam J. Thrombosis of the cerebral veins and sinuses. N Engl J Med 2005 Apr 28; 352:1791-8.

3.Ehtisham A, Stern B. Cerebral venous thrombosis: a review. Neurologist. 2006 Jan;12:32-8. PMID: 16547444.

4.Selim M, Fink J, Linfante I, Kumar S, Schlaug G, Caplan LR. Diagnosis of cerebral venous thrombosis with echo-planar-T2*-weighted magnetic resonance imaging. Arch Neurol. 2002 Jun; 59(6):1021-6. PMID: 12056941.

5.Idbaih A, Boukobza M, Crassard I, Porcher R, Bousser MG, Chabriat H. MRI of clot in cerebral venous thrombosis: high diagnostic value of susceptibility-

weighted images. Stroke 2006 Apr;37(4):991-995. PMID: 16484607.

6.Gillum LA, Mamidipudi SK, Johnston SC. Ischemic stroke risk with oral contraceptives : a meta-analysis. JAMA. 2000 Jul 5;284(1):72-8. PMID: 10872016.

7. Rousseaux $M$, Lesoin $F$, Barbaste $P$, Jomin $M$. Infarctus cérébelleux pseudotumoral d’origine veineuse. Rev Neurol (Paris). 1988;144(3):209-11. PMID: 3368694.

8.Einhäupl K, Bousser MG, Bruijn SF, Ferro JM, Martinelli I, Masuhr F, Stam J. EFNS guideline on the treatment of cerebral venous and sinus thrombosis. Eur J Neurol. 2006 Jun 06;13(6):553-9.

9. Gosk-Bierska I, Wysokinski W, Brown RD, Karnicki K, Grill D, Wiste H, et al. Cerebral venous sinus thrombosis: incidence of venous thrombosis recurrence and survival. Neurology. 2006 Sep 12;67(5):814-9. PMID: 16966543. 